\title{
Exacerbation of postural tremor with emergence of parkinsonism after treatment with neuroleptic drugs
}

\author{
E D Playford, T C Britton, P D Thompson, D J Brooks, L J Findley, C D Marsden
}

\begin{abstract}
Neuroleptic medication in three patients with prior isolated postural arm tremor led to a conspicuous deterioration; the postural tremor increased in amplitude, tremor appeared at rest, and other signs of mild parkinsonism developed. Withdrawal of neuroleptic drugs led to improvement in tremor and disappearance of parkinsonism. Positron emission tomography showed no reduction in uptake of $\left[{ }^{18} \mathrm{~F}\right]$ dopa into nigrostriatal terminals suggesting that these patients did not have Parkinson's disease. Neuroleptic drugs can convert postural essential arm tremor into that characteristic of Parkinson's disease in patients with no evident nigrostriatal lesion.
\end{abstract}

(F Neurol Neurosurg Psychiatry 1995;58:487-489)

Keywords: postural tremor; parkinsonism; neuroleptic drugs

Postural tremors of large amplitude with tremor at rest are a source of diagnostic confusion. The postural tremor of essential tremor typically does not have a rest component. ${ }^{1-3}$ When there are coexisting signs of parkinsonism, and a rest tremor, postural tremor is interpreted as representing one expression of parkinsonian tremor. ${ }^{4}$ We describe three patients referred because of a pronounced exacerbation of a previously isolated postural tremor of the arms after the ingestion of neuroleptic drugs. All exhibited both postural tremor and rest tremor of the arms as well as other signs of parkinsonism, but striatal $\left[{ }^{18} \mathrm{~F}\right]$ dopa uptake on PET was within the normal range. After withdrawal of neuroleptic drugs, the rest component of tremor disappeared, postural tremor improved, and other signs of parkinsonism resolved.

\section{Methods}

POSITRON EMISSION TOMOGRAPHY

Positron emission tomography was performed with a CTI 981/08/12 tomograph (CTI Knoxville, TN, USA) yielding 15 simultaneous planes with an axial FWHM resolution of $7 \mathrm{~mm}$ and an in plane resolution of $8.5 \mathrm{~mm} .^{2}$
Correction for tissue attenuation of $511 \mathrm{keV}$ radiation was measured with an external ${ }^{68} \mathrm{Ge}$ ring. Each patient had an individually moulded thermoplastic head support to minimise movement throughout the scan. The patients were no longer taking neuroleptic drugs, and antiparkinsonian medication was stopped for 24 hours before the scan. One hour before the scan patients were given 100 $\mathrm{mg}$ of carbidopa, a peripheral decarboxylase inhibitor.

$\left[{ }^{18} \mathrm{~F}\right]$ dopa $(3-5 \mathrm{mCi}$ in $10 \mathrm{ml}$ of normal saline) was infused intravenously over two minutes. Scanning began at the start of tracer infusion with sequential one minute time frames increasing to five minute time frames to provide a total of 25 time frames over 90 minutes.

Region of interest analysis was performed on a SUN 3/60 workstation using image analysis software (Analyze 3.0 Biodynamic Research Unit, Mayo Clinic, MN, USA). The positions of occipital and striatal regions of interest were defined on an integrated image of tissue activity created by summing time frames containing ${ }^{18} \mathrm{~F}$ activity collected $30-90$ minutes after injection of $\left[{ }^{18} \mathrm{~F}\right]$ dopa. Regions of interest were then placed by inspection in a standard arrangement: head of caudate nucleus (one square region each side of $8.2 \mathrm{~mm}^{2}$ ), dorsal putamen (three square regions each, of $8.2 \mathrm{~mm}^{2}$ ), and occipital lobe (one circular region each side of 32.8 $\mathrm{mm}$ diameter). All regions were defined on the two optimum adjacent planes and side to side average values for each anatomical structure were calculated. Regional time activity curves were plotted and the data from 30-90 minutes analysed with a modified multiple time graphical analysis technique. Occipital tissue was used as a non-specific reference input function. After decay correction, region/occipital activity $v$ integrated occipital/occipital activity was plotted. This plot is linear for data collected over 30 to 90 minutes of real time and the gradients obtained can be regarded as influx constants, $\mathrm{Ki}$, which reflect the rate of striatal decarboxylation of $\left[{ }^{18} \mathrm{~F}\right]$ dopa and its storage as $\left[{ }^{18} \mathrm{~F}\right]$ dopamine and its metabolites. Results were compared with those obtained from a group of 30 normal subjects and a group of 29 patients with established Parkinson's disease. 


\section{Patients}

CASE HISTORIES

Case 1

A 68 year old woman with an eight month history of mild postural arm tremor noted a pronounced increase in the amplitude of tremor and the appearance of a rest tremor after a course of metoclopramide $(10 \mathrm{mg}$ twice daily) for nausea. She also developed generalised stiffness, and had difficulty dressing herself and turning in bed. She became unsteady when walking and tended to fall. There was no family history of tremor although her mother was said to have had Parkinson's disease. The effect of alcohol on her tremor was not known. Madopar 125 (twice daily) was prescribed and continued for 11 months, with considerable benefit.

Examination while on metoclopramide and Madopar showed an expressionless face and a reduced blink rate. Tongue and hand movements were slow and finger movements were of small amplitude. There was distal but not proximal rigidity of all four limbs. A pronounced bilateral postural and rest arm tremor were evident. She walked with a stooped posture and took small shuffling steps with poor arm swing. There were also occasional dyskinetic movements of the left leg. Surface EMG recordings from forearm muscles showed a $5 \mathrm{~Hz}$ postural tremor and an intermittent $4-4.5 \mathrm{~Hz}$ rest tremor of the arm. After metoclopramide and Madopar were stopped, the rest tremor subsided during the subsequent months, but the postural tremor persisted. When holding a glass with the right hand the postural tremor developed a pronation-supination quality. Bradykinesia and rigidity were no longer present and her posture and arm swing were normal when walking. An $\left[{ }^{18} \mathrm{~F}\right]$ dopa scan showed normal striatal tracer uptake (table).

\section{Case 2}

A 33 year old man had a history of postural tremor of the arms since the age of 12 years. There was no family history of tremor and the tremor was not relieved by alcohol. The tremor was mild at its onset but had slowly increased in severity with the passage of time. At age 32 he was treated for depression with injections of depot flupenthixol (20-40 mg) every two weeks for nine months. Within one month he complained of a large increase in the severity of the arm tremor, which had appeared at rest, and he developed jaw, leg, and trunk tremor. On examination at this time, he exhibited a staring facial expression

Mean striatal $\left.{ }^{8} \mathrm{~F}\right]$-dopa influx constants (Ki)

\begin{tabular}{lll}
\hline & Putamen & Caudate \\
\hline Case 1 & 0.0095 & 0.0098 \\
Case 2 & 0.0097 & 0.0114 \\
Case 3 & 0.0075 & 0.0090 \\
Normal Range(SD) & $0.0098(0.0011)$ & $0.0107(0.0019)$ \\
(n= 30) & & \\
$\begin{array}{l}\text { Parkinson's disease (SD) } \\
\text { (n=29) }\end{array}$ & $0.0043(0.0012)$ & $0.0084(0.0024)$ \\
\hline
\end{tabular}

with infrequent blinking and an open mouth with jaw tremor. There was a pronounced rest tremor of both upper and lower limbs and a large amplitude postural tremor of both arms. The tremor interfered with fine manual tasks and rapid alternating finger movements were slow, clumsy, and of small amplitude. Cogwheel rigidity was present in all limbs. $\mathrm{He}$ stood with a stooped posture and walked with shuffling steps and little arm swing. Surface EMG recordings showed a widespread $4 \mathrm{~Hz}$ tremor at rest, which increased to $5 \mathrm{~Hz}$ on action.

The tremor improved on a combination of orphenadrine (50 mg twice daily), Sinemet 125 (four times daily), clonazepam ( $3 \mathrm{mg}$ three times a day), and propranolol (160 mg twice daily). Flupenthixol was stopped but three months later he still showed an expressionless face, and a rest and postural tremor although the tremors were less severe than at this initial presentation. Limb rigidity and upper limb bradykinesia had also improved, as had his gait. The parkinsonism subsequently recovered in the next six months; the rest tremor disappeared but postural arm tremor persisted. Striatal $\left[{ }^{18} \mathrm{~F}\right]$ dopa uptake was normal.

\section{Case 3}

A 67 year old woman had a lifelong history of a postural tremor and a strong family history of a similar disorder. She also had a long history of intermittent vertigo for which she took small doses of prochlorperazine $(5 \mathrm{mg})$ on an irregular basis (although this fact did not emerge until some time after she was first seen). She was referred because of increasing severity of her tremor which had begun to interfere with fine manual tasks. One year before this she had been treated with lofepramine for depression. After this she became aware, for the first time, of a symmetric rest tremor of the hands. The tremor was still present on posture and action. Examination at this time showed a mild reduction in spontaneous facial expression and a severe postural tremor of the upper limbs and occasional jaw tremor. When seated in repose the tremor appeared intermittently. There was bradykinesia of rapid alternating finger movements, with serious interruption of manual tasks by the tremor. Various drugs (including propranolol, primidone, and Sinemet) failed to help the tremor. When it emerged that she had been taking prochlorperazine, she was instructed to stop this, and within a few weeks the rest tremor settled, the amplitude of the postural and action tremor diminished, and her voluntary movements returned to normal.

She later developed a gastric carcinoma and during investigation and treatment of symptoms relating to this, was given metoclopramide on numerous occasions. During each course of metoclopramide treatment she developed a recurrence of the severe postural tremor and the rest tremor reappeared, each settling with withdrawal of the metoclopramide. Domperidone was substituted for 
the metoclopramide, with control of gastrointestinal symptoms but without worsening of the tremor. An $\left[{ }^{18} \mathrm{~F}\right]$ dopa PET showed striatal tracer uptake to be lower than in patients 1 and 2 , but still within $2.5 \mathrm{SD}$ of the normal range, and putamen uptake was more than 2.5 SD above the range in Parkinson's disease.

\section{Discussion}

These three patients exposed to neuroleptic drugs that block dopamine receptors presented with deterioration of a previously stable postural tremor with the additional appearance of a rest tremor and other parkinsonian signs. Rest or postural tremors may occur in neuroleptic induced parkinsonism. ${ }^{5}$ In the present cases, there was a pre-existing postural tremor that was profoundly exacerbated by treatment with neuroleptic drugs, which also provoked rest tremor. In two of the three patients, treatment with levodopa improved the tremor and associated parkinsonian signs, presumably by causing a degree of reversal of the dopamine receptor blockade caused by the prior neuroleptic drug treatment.

The question arises as to whether all had underlying, subclinical depletion of nigrostriatal dopamine, with unmasking of parkinsonism by neuroleptic drugs, the prior postural tremor being the first sign of mild Parkinson's disease. Drug induced parkinsonism may be reversible even in cases of latent Parkinson's disease with typical pathological changes. ${ }^{6}$

The relation of essential tremor and Parkinson's disease has been the subject of much debate. Some studies have suggested that patients with essential tremor have a higher risk of developing Parkinson's disease ${ }^{7}$ whereas others have not found any association. ${ }^{8}$ The second view is supported by the finding of normal nigrostriatal $\left[{ }^{18} \mathrm{~F}\right]$ dopa uptake in a recent study of isolated and familial (essential) postural tremor. ${ }^{9}$ This is consistent with the absence of evident neuropathological abnormality in essential tremor. ${ }^{10}$ In the present cases, measurements of $\left[{ }^{18} \mathrm{~F}\right]$ dopa uptake into the putamen and caudate nucleus, which provide an estimate of the functional integrity of nigrostriatal nerve terminals, showed values within the normal range, unlike the pronounced reduction seen in Parkinson's disease. ${ }^{11}$ These three patients thus seem to have an essential tremor with a normal nigrostriatal dopaminergic system. Yet neuroleptic drug treatment caused worsening of their postural tremor and the appearance of rest tremor, with other signs of parkinsonism.

In primates, lesions in the ventral tegmental area of the midbrain interrupting both the dentatorubro-olivary pathway (the central tegmental tract) and the nigral efferents to the striatum are required to produce a 3-5 $\mathrm{Hz}$ postural and rest tremor. ${ }^{12-14}$ Lesions of the nigrostriatal tract alone are not sufficient to produce tremor. Lesions of the dentatorubro-olivary tract alone, particularly with administration of harmaline, result in a 5-8 $\mathrm{Hz}$ postural tremor. In patients with pre-existing postural essential tremor it is likely that overactivity of the cerebellorubroolivary loop is present ${ }^{15}$ but $\left.{ }^{\left[{ }^{18}\right.} \mathrm{F}\right]$ dopa uptake is normal. ${ }^{9}$ Antagonism of dopamine binding to striatal receptors by neuroleptic drugs may then create a reversible, pharmacological lesion of nigrostriatal projections, which in the presence of a postural tremor, mimics the combined lesion seen in experiments with monkeys, to produce a postural and rest tremor. Indeed, drugs that decrease dopamine concentrations can induce a postural tremor in monkeys with dentatorubroolivary lesions that is abolished by levodopa. ${ }^{16}$ Thus these three patients mimic in humans the experimental findings on subhuman primates. Rest tremor seems to require deficits in both dentatorubro-olivary and nigrostriatal dopamine systems. Recent studies with $\mathrm{H}_{2}{ }^{15} \mathrm{O}$ PET have shown cerebellar and rubral overactivity in patients with essential tremor. ${ }^{17}$ The next question is why patients with Parkinson's disease exhibit a rest tremor, for there is no known pathological abnormality of the dentatorubro-olivary system in this disease.

1 Larsen TA, Calne DB. Essential tremor. Clin Neuropharmacol 1983;6:185-206.

2 Salisachs P, Findley LJ. Problems in the differential diagnosis of essential tremor. In: Findley LJ, Capildeo R, eds. Movement disorders: tremor. London: MacMillan Press. 1984:219-24.

3 Koller WC, Rubino FA. Combined resting-postural tremors. Arch Neurol 1985;42:683-4.

4 Lance JW, Schwab RS, Peterson EA. Action tremor and the cogwheel phenomenon in Parkinson's disease. Brain 1963;86:95-110.

5 Tarsy D. Neuroleptic induced movement disorders. In: Quinn NP, Jenner PG, eds. Disorders of movement. Quinn NP, Jenner PG, eds. Disorder
London: Academic Press, 1989:361-93.

6 Rajput A, Rozdilsky B, Hornykiewicz O, et al. Reversible drug-induced parkinsonism. Clinicopathological study drug-induced parkinsonism. Clinicopath
of two cases. Arch Neurol 1982;39:644-6.

7 Geraghty JJ, Jankovic J, Zetusky WJ. Association between essential tremor and Parkinson's disease. Ann Neurol 1985;17:329-33.

8 Cleeves L, Findley LJ, Koller W. Lack of association between essential tremor and Parkinson's disease. Ann Neurol 1988;24:23-6.

9 Brooks DJ, Playford ED, Ibanez V, et al. Isolated tremor and disruption of the nigrostriatal dopaminergic system: An ${ }^{18}$ F-dopa study. Neurology 1992;42:1554-60.

10 Rajput AH, Rozdilsky B, Avig L, Rajput A. Clinicopathological observations in essential tremor: a report of pix cases. Neurology 1991;41:1422-4.

11 Brooks DJ, Ibanez V, Sawle GV, et al. Differing patterns of striatal ${ }^{18} \mathrm{~F}$-dopa uptake in Parkinson's disease, multiof striatal ${ }^{8} \mathrm{~F}$-dopa uptake in Parkinson's disease, multiple system atrophy, and prog

12 Poirier LJ, Sourkes TL, Bouvier G, Boucher R, Carabin $S$. Striatal amines, experimental tremor and the effect of harmaline in the monkey. Brain 1966;89:37-52.

13 Poirier LJ, Filon M, Larochelle L, Pechadre JC. Physiopathology of experimental parkinsonism in the monkey. Can f Neurol Sci 1975;2:255-63.

14 Lamarre Y. Tremorgenic mechanisms in primates. $A d v$ Neurol 1975;10:23-4.

15 Colebatch JG, Findley LJ, Frackowiak RSJ, et al. Preliminary report: activation of the cerebellum in essential tremor. Lancet 1990;336:1028-30.

16 Larochelle L, Bedard P, Poirier LJ, Sourkes TL. Correlative neuroanatomical and neuropharmacological study of tremor and catatonia in the monkey. Neuropharmacology 1971;10:273-88

17 Wills AJ, Jenkins IH, Thompson PD, Frackowiak RSJ, Findley LJ, Brooks DJ. Red nuclear and cerebellar but no olivary activation associated with essential tremor: a no olivary activation associated with essential tremor: a
positron emission tomography study. Ann Neurol positron emissio 